\title{
AC 2007-1896: DESIGN OF PHOTOVOLTAIC SYSTEMS FOR MUNICIPAL AND SCHOOL BUILDINGS IN OCEAN CITY, NEW JERSEY
}

Peter Mark Jansson, Rowan University

Ryan Elwell, Rowan University 


\title{
Design of Photovoltaic Systems for Municipal and Public School Buildings in Ocean City, New Jersey
}

\begin{abstract}
As part of the Junior/Senior Engineering Clinic experience at Rowan University ${ }^{1-2}$, students were able to directly participate in the engineering design, specifications, feasibility analysis and specification of photovoltaic (PV) systems for the City of Ocean City's school and public buildings. The New Jersey Clean Energy Program ${ }^{3}$ provides some of the most lucrative rebates for renewable energy system installations in the nation, and this clinic experience allowed engineering students to directly participate in a growing renewable energy market while learning more about the electrical design of PV systems. In order to assure that their PV systems would be economically feasible and well designed, the City of Ocean City (OC) and the OC Board of Education hired Integrated Systems (a consulting engineering group) to determine appropriate designs and plans for each of the twenty buildings they were considering. The feasibility study determined that ten buildings were good candidates for the PV systems. The consulting company (acting as an industry affiliate to the College of Engineering) engaged a professor and students in the work to encourage expansion of the technical labor pool in this important area. The purpose of the project was to provide a final report on the feasibility of PVs for each building in the study, including analysis of electric usage history, current electric usage trends, long-term cost/benefit analysis, overall structural integrity of the roofs to support the added loads, layout and design of the PV system itself as well as a wiring diagram for interconnection with the utility. The result was an engineering analysis which prepared the City of Ocean City and OC School Board to make key investment decisions and proceed with the implementation of the photovoltaic systems. The impact on project-based learning is emphasized as these types of clinic experiences motivate and excite students to learn the requisite engineering skills to solve the real world problems.
\end{abstract}

\section{Introduction}

This paper details the methods used in determining the feasibility of a sizeable renewable energy photovoltaic (PV) project in Ocean City, New Jersey. The study details the process that determined the number of proposed buildings owned by the City of Ocean City and the Ocean City Board of Education which are good candidates for taking advantage of this clean and profitable way to produce energy. Early in 2006 the New Jersey Board of Public Utilities voted to adopt an aggressive Renewable Portfolio Standard (RPS) that committed the State to incorporate $20 \%$ renewable energy sources into its electricity mix by the year 2020 . In addition, the RPS identified that $2 \%$ would be set aside specifically for photovoltaics - amounting to 1500 MW in 2020. This represents one of the largest commitments to PV in the United States. ${ }^{4}$ In the spring of 2006 the City of Ocean City solicited bids for consulting engineering services to assist them in determining the feasibility of PV for many of their city and school buildings, and the successful firm was Integrated Systems. A professor in the College of Engineering at Rowan University works closely with that firm and identified the opportunity to engage engineering students in the project as part of an ongoing innovative Industry Affiliates arrangement which engages local industry in the educational process. This would also benefit the students, the engineering company and field (since more engineers are needed in NJ with PV expertise). 
During the summer break and Autumn semester 2006 electrical and computer engineering (ECE) students, engineering alumni and an ECE professor were engaged by the firm to assist in meeting the project deliverables. The primary deliverable was an engineering assessment and associated final report on the feasibility of PV systems for each building in the study. Student design work during the summer was compensated as part of an internship with the Industrial Affiliate, the work performed by the students during the school year was part of their engineering clinic coursework for credit. To commence the assessment the electric usage history and current electric usage trends for each of the study's buildings had to be gathered, summarized and analyzed. Building plans had to be collected and reviewed in order to evaluate the structure's azimuth, roof area and tilt, as well as the overall structural integrity of the roofs to support the added loads of PV systems. The 21 buildings investigated were summarized in a brief feasibility matrix developed by Integrated Systems and completed with the aid of the students.(see Figure 1) A preliminary layout and design of the PV system itself as well as a wiring diagram for interconnection with the utility needed to be created for buildings that made it past the first screening. This was in order to evaluate those systems for $\mathrm{NJ}$ rebate eligibility ${ }^{5}$ and generate the requisite applications for the NJCEP rebates. Finally, those systems that were eligible for rebates became part of a long-term cost/benefit analysis that incorporated the engineering cost estimates for each system, the maintenance costs, the City of Ocean City's bond fees and interest and the benefits stream from energy savings and Solar Renewable Energy Certificate ${ }^{6}$ value.

\begin{tabular}{|c|c|c|c|c|c|c|c|c|c|c|c|c|c|c|c|}
\hline & 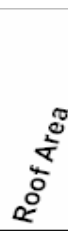 & 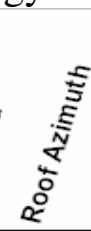 & क & 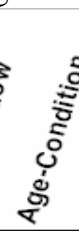 & 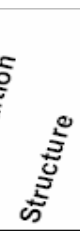 & $\begin{array}{c}\text { के } \\
\text { बे } \\
\text { ১0 }\end{array}$ & 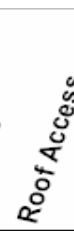 & 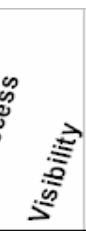 & 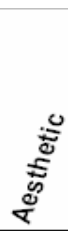 & $\underset{0}{\stackrel{0}{0}}$ & $\frac{5}{5}$ & $\begin{array}{c}\overrightarrow{0} \\
\text { है } \\
\text { है } \\
\text { के }\end{array}$ & $\underset{0}{\frac{\pi}{x}}$ & ह & $\begin{array}{l}\text { s } \\
\text { के } \\
\text { है } \\
\text { के } \\
\text { के }\end{array}$ \\
\hline New Public Works & () & () & () & () & $\otimes$ & $\otimes$ & $\otimes$ & $\otimes$ & () & () & () & $\otimes$ & () & $\mathrm{Hi}$ & 450 \\
\hline OC High School & () & () & () & () & $\otimes$ & $\otimes$ & $\otimes$ & $\otimes$ & $\otimes$ & () & () & $\otimes$ & () & $\mathrm{Hi}$ & 750 \\
\hline Cultural \& Aquatic Ctr & $\otimes$ & () & () & () & $\otimes$ & $\otimes$ & $\otimes$ & $\otimes$ & $\otimes$ & () & () & $\otimes$ & () & $\mathrm{Hi}$ & 140 \\
\hline Sports - Civic Ctr & $\otimes$ & () & () & $\otimes$ & $\otimes$ & () & $\otimes$ & () & () & () & $\otimes$ & $\otimes$ & 궁 & $\mathrm{Hi}$ & 100 \\
\hline PL - Fire Headqrtrs & () & () & () & NA & NA & () & NA & () & () & () & () & $\otimes$ & () & & 175 \\
\hline Intermediate School & () & () & () & $\otimes$ & $\otimes$ & $\otimes$ & () & $\otimes$ & $\otimes$ & () & () & $\otimes$ & 궁 & $\mathrm{Hi}$ & 600 \\
\hline PL - Fire Sta No. 3 & $\otimes$ & () & () & NA & NA & () & NA & () & () & () & () & $\otimes$ & () & & 90 \\
\hline 800 Boardwalk & $\otimes$ & () & () & $\otimes$ & $\otimes$ & () & $\otimes$ & () & $\otimes$ & () & () & $\otimes$ & () & $\mathrm{OK}$ & 50 \\
\hline Int. School Maint. & $\otimes$ & () & () & $\otimes$ & $\otimes$ & () & $\otimes$ & () & $\otimes$ & () & () & $\otimes$ & () & OK & 40 \\
\hline Community Dev. E-W & $\otimes$ & () & () & $\otimes$ & $\otimes$ & $\otimes$ & $\otimes$ & $\otimes$ & () & () & () & $\otimes$ & $\otimes$ & & 20 \\
\hline Music Pier & () & () & () & $\otimes$ & $\otimes$ & $\otimes$ & $\otimes$ & () & () & () & $\otimes$ & $\otimes$ & $\otimes$ & $\mathrm{Hi}$ & 500 \\
\hline Fire Headquarters & $\otimes$ & () & () & $\otimes$ & $\otimes$ & $\otimes$ & $\otimes$ & $\otimes$ & $\otimes$ & () & $\otimes$ & $\otimes$ & $\otimes$ & & 50 \\
\hline Primary School & $\otimes$ & () & $\otimes$ & $\otimes$ & $\otimes$ & $\otimes$ & $\otimes$ & $\otimes$ & $\otimes$ & () & $\otimes$ & $\otimes$ & $\otimes$ & $\mathrm{Hi}$ & 250 \\
\hline Humane Society E-W & () & () & () & $\otimes$ & $\otimes$ & () & $\otimes$ & $\otimes$ & () & () & () & $\otimes$ & $\otimes$ & & 20 \\
\hline OC Munic. Airport & $\otimes$ & $\otimes$ & () & $\otimes$ & $\otimes$ & $\otimes$ & $\otimes$ & $\otimes$ & $\otimes$ & () & $\otimes$ & $\otimes$ & $\otimes$ & & 80 \\
\hline City Hall & $\otimes$ & $\otimes$ & () & $\otimes$ & $\otimes$ & $\otimes$ & $\otimes$ & $\otimes$ & $\otimes$ & $\otimes$ & () & $\otimes$ & $\otimes$ & & 40 \\
\hline Public Works (North) & () & () & () & $\otimes$ & $\otimes$ & $\otimes$ & $\otimes$ & $\otimes$ & $\otimes$ & () & $\otimes$ & $\otimes$ & $\otimes$ & $\mathrm{OK}$ & 80 \\
\hline Fire Station No. 2 & $\otimes$ & $\otimes$ & $\otimes$ & $\bullet$ & $\otimes$ & $\otimes$ & $\otimes$ & $\otimes$ & $\otimes$ & $\otimes$ & $\otimes$ & $\otimes$ & $\otimes$ & & 50 \\
\hline Fire Station No. 3 & $\otimes$ & $\bullet$ & $\otimes$ & $\bullet$ & $\otimes$ & $\otimes$ & $\otimes$ & $\otimes$ & $\otimes$ & $\otimes$ & $\otimes$ & $\otimes$ & $\otimes$ & & 40 \\
\hline Humane Society N-S & $\otimes$ & $\bullet$ & $\otimes$ & $\otimes$ & $\otimes$ & () & $\otimes$ & $\otimes$ & $\otimes$ & $\otimes$ & () & $\otimes$ & $\otimes$ & & 20 \\
\hline OC Information Ctr & Q & $\otimes$ & $\otimes$ & $\otimes$ & $\otimes$ & (8) & $\otimes$ & $\otimes$ & $\otimes$ & $\otimes$ & $\bullet$ & $\otimes$ & $\otimes$ & & 15 \\
\hline & () & \multicolumn{2}{|c|}{ - Good } & $\otimes$ & - OK & & $\otimes$ & \multicolumn{2}{|c|}{ - Neutral } & $\otimes$ & \multicolumn{2}{|c|}{ - Issues } & - & \multicolumn{2}{|c|}{-Poor } \\
\hline
\end{tabular}

Figure 1: Initial scope of renewable energy project with feasibility ratings 


\section{Electrical Usage [Historical \& Current]}

In designing a photovoltaic (PV) system, the first engineering estimate to be made is the determination of a projected system size. There are many considerations that go into finding the maximum amount of energy that could be potentially produced by PV at a given site. One of first approaches to take is to find the absolute upper limit of production. The State of New Jersey mandates that a grid-connected photovoltaic system will not be able to receive rebates for that portion of the system that produces more energy than that which has historically been consumed on an annual basis ${ }^{5}$. Once the maximum system size is determined (using methods to be described later), historical energy usage data is also helpful in determining the percentage of the demand that the system will be expected to supply. As the Ocean City buildings were inspected, current major users of electricity were noted (HVAC systems, lighting, etc.). In some instances, a complete energy audit would be profitable to pinpoint other significant areas of demand (and also propose energy efficiency strategies). However, due to the revision of the original scope of work a more detailed audit of these features was not proposed in the man-hours budgeted.

Historical electrical energy data is a key factor in the process of integrating the PV system into the electricity supply. Because the demand in a building will vary with respect to season (especially in Public School buildings), twelve months worth of energy data was collected for various buildings of consideration in Ocean City so that they could be analyzed. Figure 2 shows the annual usage of electricity by the Ocean City. Public Schools buildings

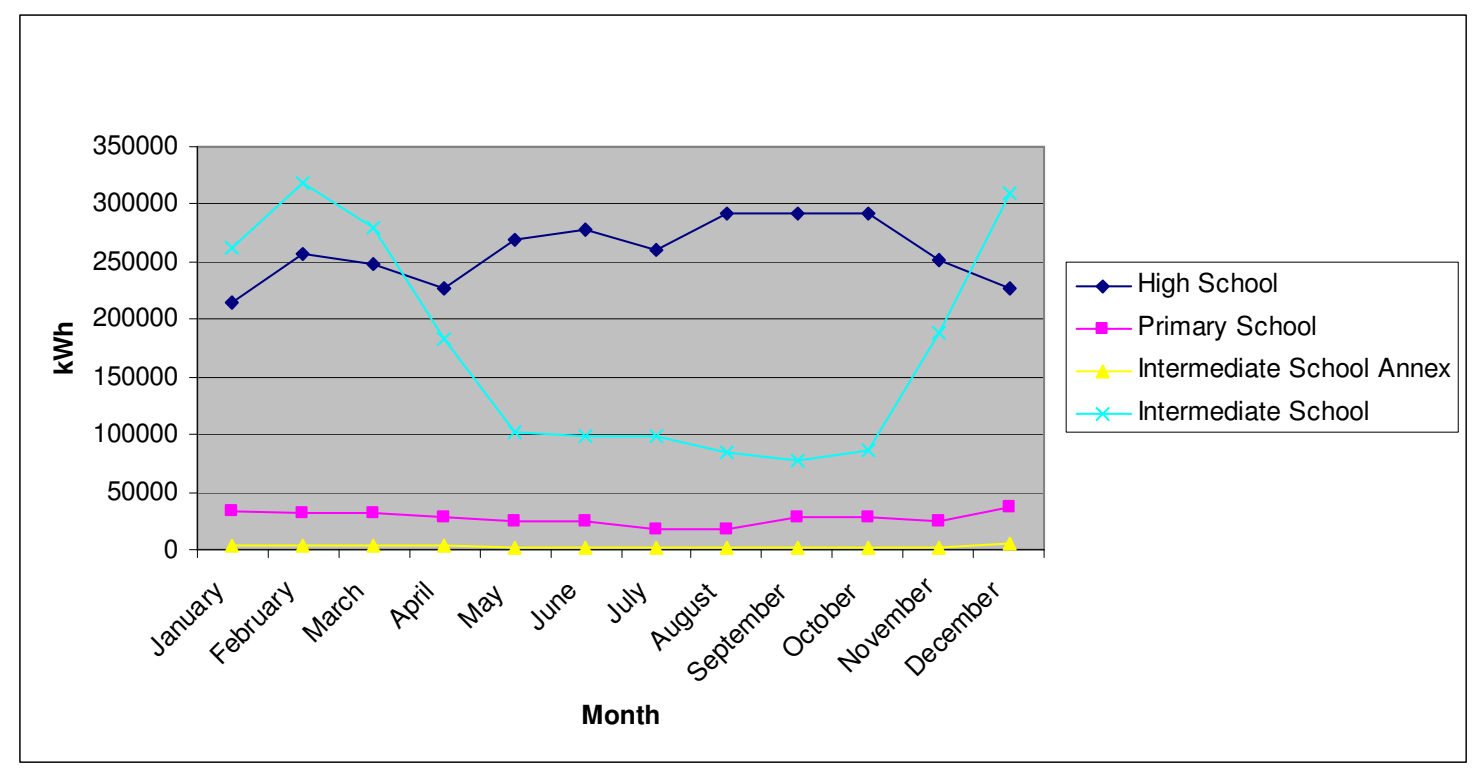

Figure 2: OC Board of Education annual electrical energy consumption

Figure 3 on the page which follows provides the summary of all City of Ocean City buildings that were included in the detailed engineering feasibility portion of the investigation. Current electrical usage information is especially important data for analyzing recently constructed buildings. This was encountered in the analysis of the New Public Works Building, which was 
completed recently in 2005. Simply looking at the energy usage from its first year could prove to be inaccurate, for a building may not reach its full functionality until its second or third year of operation. It was here that our engineering students learned first hand that maintaining a close relationship and consistent communication with the client was important so that accurate information could be gathered easily.

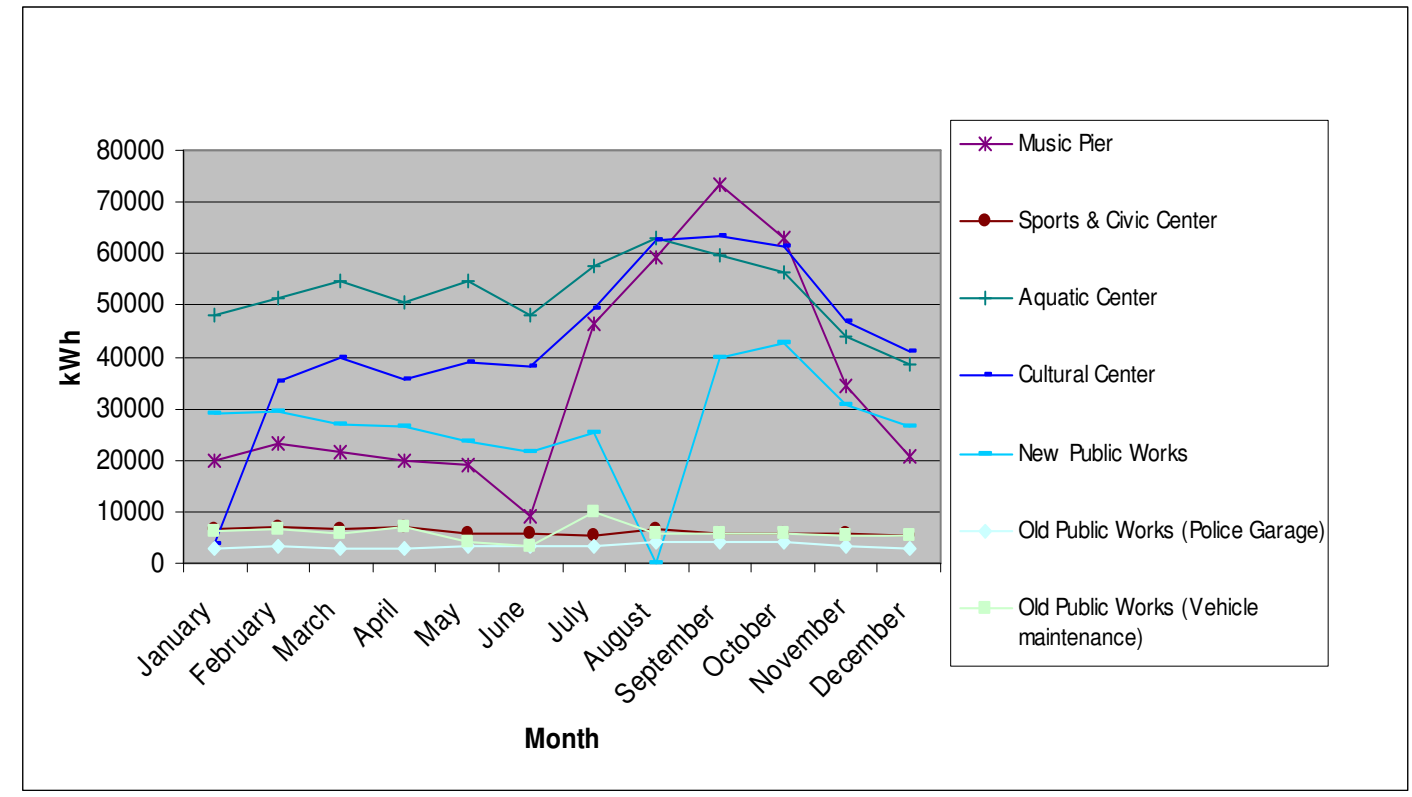

Figure 3: City of Ocean City annual electrical energy consumption

\section{Roof Analysis [Integrity, Available Reserve, Usability]}

The physical size of a photovoltaic system is constrained by the area in which the solar modules can be placed within an effective solar window (NOTE: the solar window will be described in greater detail in the section which follows). PV modules are most often placed on the roof of the building they are supplying since this does not require the cost of an additional mounting structure and is often elevated above competing shadows. Therefore analyzing the building roof becomes the next key factor in sizing the system. The solar module type that Integrated System chose for use in Ocean City was the Sunpower 220 (SPR-220), which weighs $15 \mathrm{~kg}$ with dimensions of $5.1 \times 2.6 \mathrm{ft}^{7}$. The structural integrity of the roof must be such that it can hold the desired number of modules while supporting normal expected loads. After some research on the history of the buildings in Ocean City, it was found that the age of the buildings greatly varied. While many were built within the last twenty years, some exceeded 30 years, and at least one was over fifty years old (Music Pier). The structural integrity was a key factor in the determination that only ten of the original twenty buildings were acceptable. This required communication all design professionals responsible for the structures of interest, and when they responded their input has been weighted heavily in our preliminary assessment of elements. Even further consideration is to be required when the specific structural design is determined (after the system is finalized).

Another area of consideration in the roof analysis is the amount of area available. There are two factors which can render a roof section ineligible for solar usage: shading and direction. If the roof is to be used to collect solar energy, it should be faced toward the sun (southerly in the 
northern hemisphere, and northerly if one is in the southern hemisphere). Orientations that are predominantly east, west, and especially north facing roofs will significantly take away from a roof's ability to receive adequate sunlight to justify installation of a PV system. In addition, a roof which receives much daytime shading due to trees or other buildings is an ineligible area. This matter was of little concern for most buildings considered in the scope of feasibility in Ocean City (see Figure 1), for there is little shading (little tree cover on the island), and there are few significantly sized buildings which would prove to be obstacles. In addition, roof pitch is not an issue, for most of the roofs are flat and therefore suitable for solar usage. Even buildings such as the New Public Works Building have superior potential, for the low angle of the roof allows even its north side to be used with small tilt legs added to the modules.

\section{Solar Window/Exposure (Solar PathFinder ${ }^{\mathrm{TM}}$ )}

In order to assure that buildings met the minimum solar window required by the NJCEP rebate guidelines ( $>80 \%$ in current requirements) and that the proposed systems would have favorable electric generation and paybacks the solar window needed to be determined. The solar window is the percentage of the maximum available sun exposure that a specific area will receive on an annual basis. Calculation of this value is well documented in a previous ASEE paper completed by a Rowan University student and hisprofessor. ${ }^{8}$ Thus; to complete an assessment of energy production it is desirable to determine how much of the available solar energy will find its way to the PV module on an annual basis. An important tool for this measurement is the Solar PathFinder $^{\mathrm{TM}}$. This tool can be used to find the percentage of usable solar energy during any time of year by taking a snapshot of a single site measurement. ${ }^{9-10}$ In this area of feasibility, the ten buildings of study excelled. All buildings assessed had solar windows that were either unobstructed or minimally obstructed - windows exceeded $95 \%$ of maximum available.

\section{Initial Design of PV System for Building}

In order for the amount of insolation received to be maximized, it is most often profitable to orient the PV modules to be tilted toward the sun for as much of the year as practical. This strategy was utilized in the designs for most of the buildings to maximize the available solar window. A $20^{\circ}$ tilt was proposed for the mounting racks on flat roofs, and a $15^{\circ}$ was recommended for slightly angled roofs according to the azimuth angle of the sun. The paper previously cited $^{8}$ describes why these angles are quite suitable for the southern New Jersey area. It was necessary to set certain benchmarks along the way in the design of each system. For this reason, initial designs were formulated, detailing the location of the modules in the buildings of study for which sufficient measurements had been gathered. These plans allowed both the consultant as well as the client to visualize the work that had been done to that point. A preliminary design was also necessary for the initiation of the rebate process for the New Jersey Clean Energy Program (NJCEP). This process required technical worksheets to be completed which require detailed information about the PV equipment to be used, installation and interconnection information, and calculations for incentive (rebate) request. Two examples of these summary designs can be seen in Figures 4 and 5. The estimated size of the system is important for many reasons which are related to subsequent feasibility issues: 1) Choosing the 


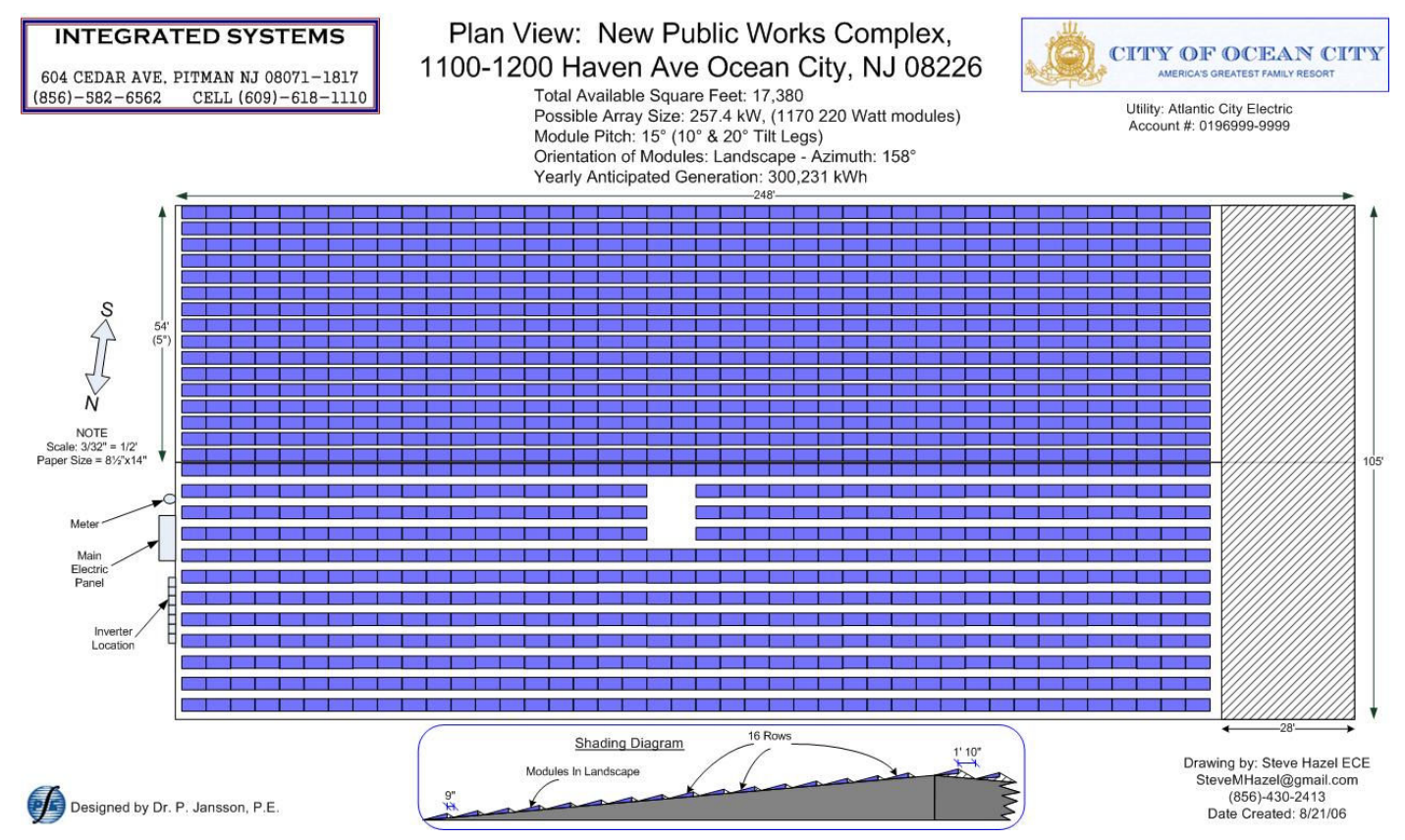

Figure 4: Initial design for New Public Works Building

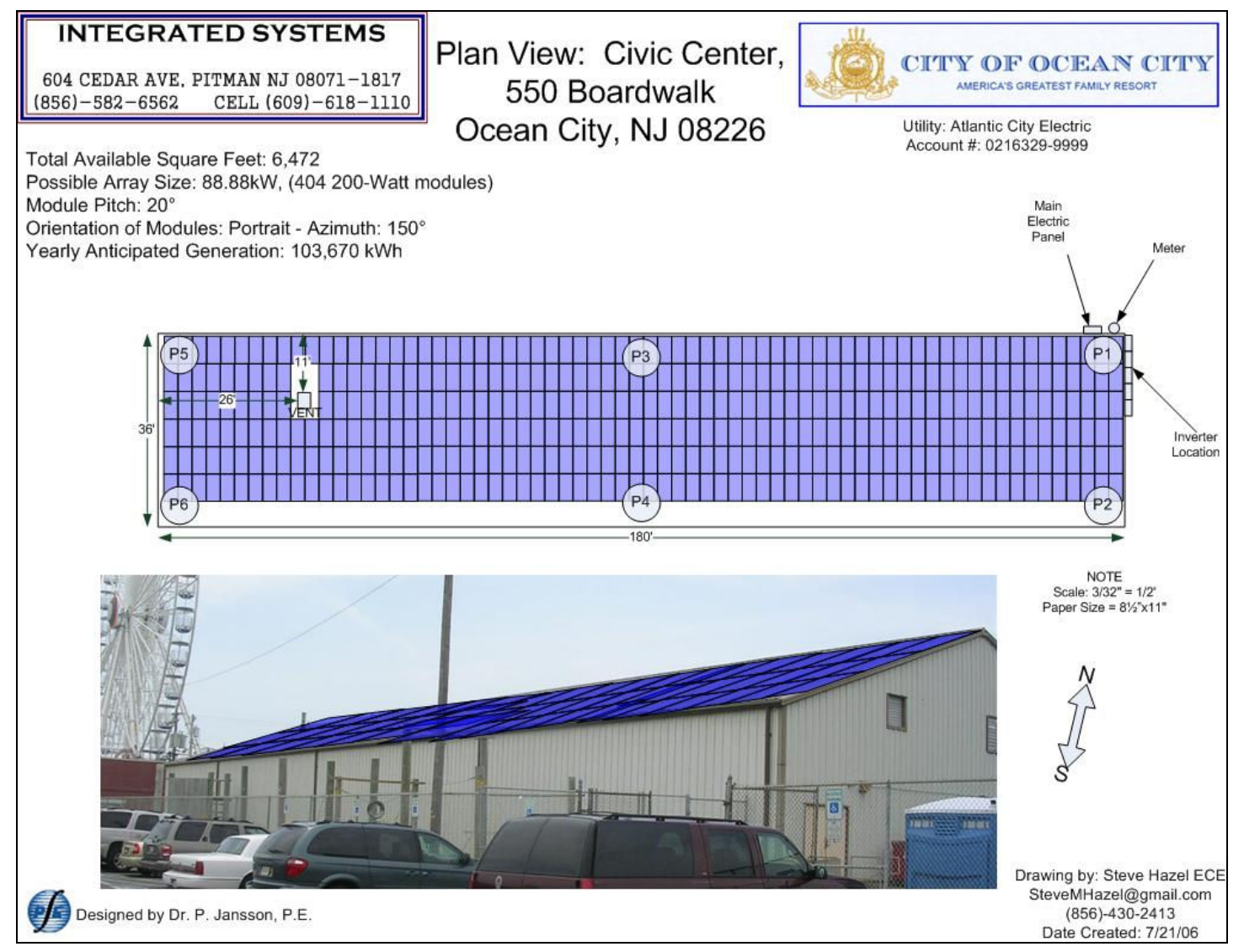

Figure 5: Initial design for Civic Center 
matching inverter(s) and wiring strategy, 2) application process for the New Jersey Clean Energy Program (NJCEP), and 3) calculation of long-term economic benefits.

\section{Wiring design}

The transmission path of power collected by the solar array is as follows: the DC power travels from the modules into a DC disconnect switch, and is then connected to the input of an inverter. The inverter is a powerful electronic device responsible for the conversion from DC to AC power so that it can be implemented into the building's single or three-phase power system. According to the National Electric Code ${ }^{11}$ wire must be sized for the PV system to assure there are less than 5\% losses. For the runs we have developed our estimated losses are sized to assure less than $2 \%$ loss.

\section{Estimate of Benefits (kWh, $\mathrm{kW}$ reduction, S-RECs, etc.)}

Having selected a system output size compatible with the building of interest, it was desirable to determine the extent that the community of Ocean City would benefit from the project. The initial high cost of an entire system is significantly reduced by extensive benefits of PV systems in New Jersey, and a numerical representation is important as an encouragement to the client of the future profits they can expect. The immediate returns come in the form of NJCEP rebates and Solar Renewable Energy Certificates (SRECs) ${ }^{6}$. The rebates themselves are able to cover about $50 \%$ of the cost of the project and are awarded immediately after the system has passed inspection. Rebate amounts are relative to the size of the individual systems. SRECs are highly valued tradable commodities which are acquired per each $1000 \mathrm{kWh}$ of energy produced. In the 2005 reporting year (Aug 2004-Aug 2005) these were valued at \$200/MWh on average in 2006 (June 2005-June 2006) the average trade was \$204/MWh ${ }^{12}$ These, along with the overall energy savings due to the system itself, represent the total benefits of the client's investment. The benefits of the Ocean City project are shown in Figure 6 where estimated annual energy production is compared to annual energy consumption (with percentage listed). PV System costs and applied for rebate amounts are given in Figure 7. The City of Ocean City is able to benefit from the large roof area of the Sports \& Civic Center without violating the NJCEP mandate for producing more than a building's typical annual usage; this is possible because the systems are treated as one according to NJCEP, and the overall production does not exceed the total consumption. 


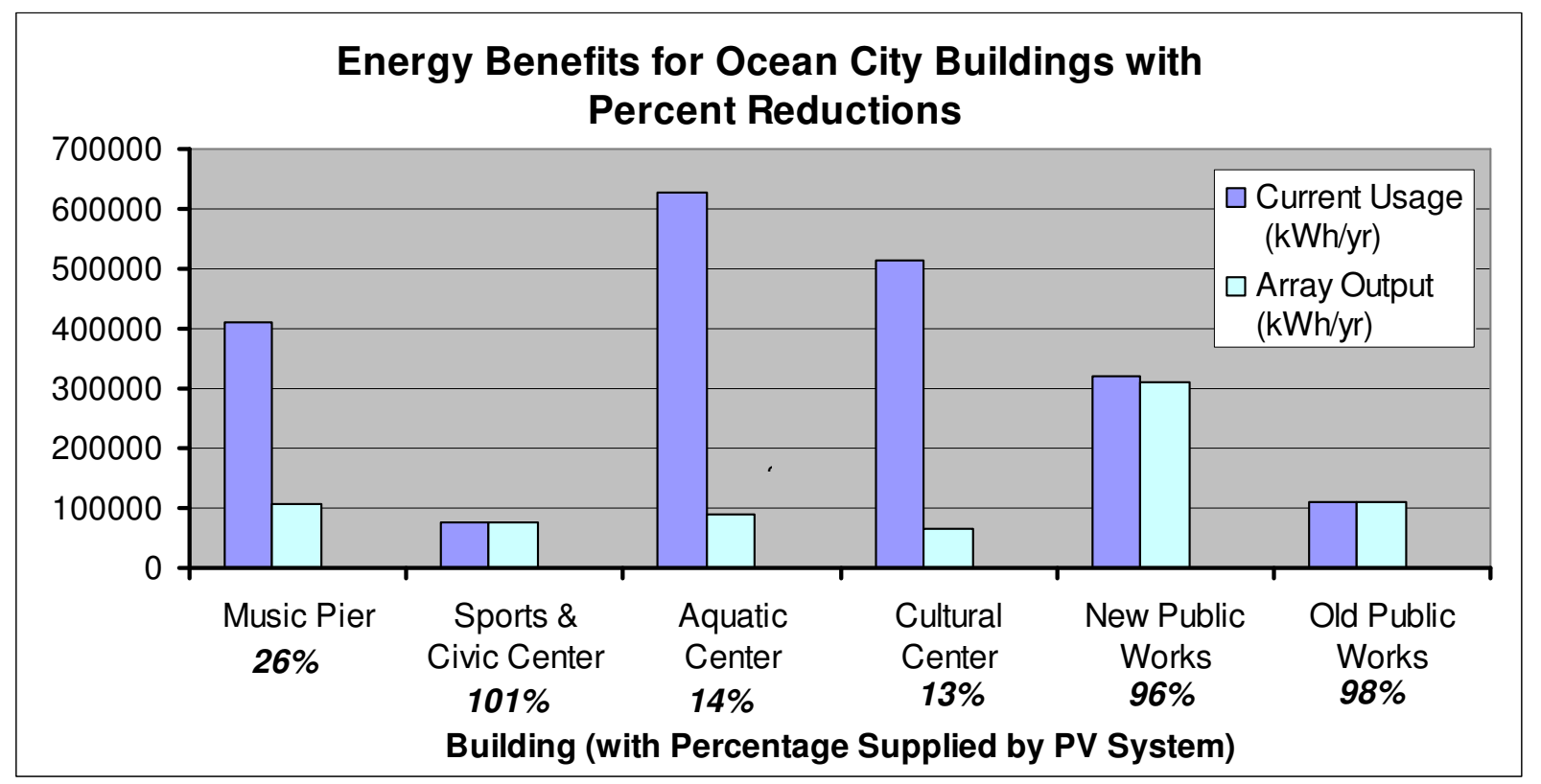

Figure 6: Estimate of energy benefits for select buildings

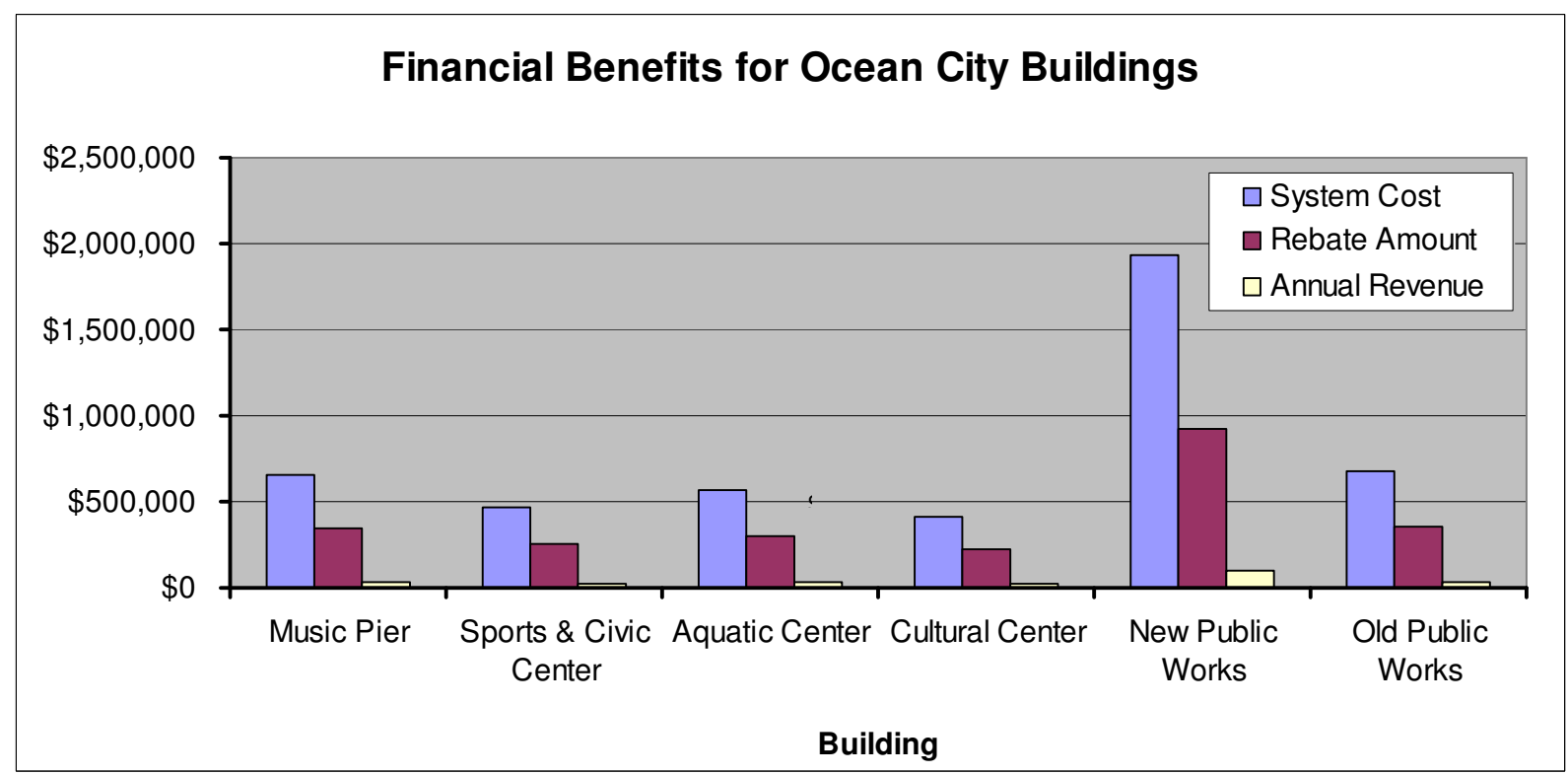

Figure 7: Estimate of financial benefits for select buildings

\section{Overall Feasibility Assessment (Engineering and Economic)}

The final product of the research conducted on the buildings is the comprehensive engineering and financial analysis report - the engineer's stamp of approval - on which buildings have passed the test. The decision still lies in the hands of the client as to whether the system will be built; therefore, the cost analysis is of even more importance. Table 1 shows the important figures 
which will allow the City of Ocean City to make the key decisions as to their way of funding the project. The preliminary PV system designs for this portion of the project show that the performance of the seven (7) public building systems could reduce electric energy use for the City by $780,000 \mathrm{kWh}$ annually and save over $\$ 100,000$. In addition, the City would save nearly $1,000,000$ pounds of greenhouse gas emissions (over 465 tons) annually to mitigate the threat of global climate change especially critical to the future viability of a shore community. The summary table below shows that the NJCEP rebates could cover over 50\% of the PV system installation costs (assuming a price of $\$ 7.50$ per watt installed) and that the systems for the selected buildings could generate, on average, $45 \%$ of the building's electrical needs.

Table 1: Engineering \& Economic Assessment for City of Ocean City buildings

\begin{tabular}{|r|r|r|r|r|r|r|}
\hline Building & \multicolumn{1}{|c|}{$\begin{array}{c}\text { System } \\
\text { Cost }\end{array}$} & $\begin{array}{c}\text { Rebate } \\
\text { Amount }\end{array}$ & $\begin{array}{c}\text { Annual } \\
\text { Revenue }\end{array}$ & $\begin{array}{c}\text { Annual } \\
\text { SRECs }\end{array}$ & $\begin{array}{c}\text { Total } \\
\text { Revenue }\end{array}$ & $\begin{array}{c}\text { Payback } \\
\text { (years) }\end{array}$ \\
\hline Music Pier & $\$ 658,350$ & $\$ 343,230$ & $\$ 14,747$ & $\$ 21,067$ & $\$ 35,814$ & 8.8 \\
\hline Sports \& Civic Center & $\$ 471,900$ & $\$ 256,220$ & $\$ 10,571$ & $\$ 15,101$ & $\$ 25,671$ & 8.4 \\
\hline Aquatic Center & $\$ 567,600$ & $\$ 300,880$ & $\$ 9,990$ & $\$ 18,163$ & $\$ 28,153$ & 9.5 \\
\hline Cultural Center & $\$ 409,200$ & $\$ 226,960$ & $\$ 7,857$ & $\$ 13,094$ & $\$ 20,951$ & 8.7 \\
\hline New Public Works & $\$ 1,930,500$ & $\$ 921,160$ & $\$ 37,066$ & $\$ 61,776$ & $\$ 98,842$ & 10.2 \\
\hline Old Public Works & $\$ 683,100$ & $\$ 354,780$ & $\$ 16,394$ & $\$ 21,859$ & $\$ 38,254$ & 8.6 \\
\hline TOTAL & $\$ 4,720,650$ & $\$ 2,403,230$ & $\$ 96,624$ & $\$ 151,061$ & $\$ 247,685$ & 9.4 \\
\hline
\end{tabular}

During this project the client had not requested a life cycle assessment (LCA) be preformed for either the modules or the PV systems. It is generally accepted that PV modules will recover the energy used to manufacture them within the first 18-24 months of their operation (depending upon whether they are made of crystalline or amorphous materials). It was not within the scope of this study to perform a detailed LCA for the components. Modules were warranted by the manufacturer for in excess of $85 \%$ output for 25 years, inverters were warranted for 10 years. In addition, the engineering analysis included an economic model which produced multiple outputs of the economic value of the combined ( 7 system) project. The model considered the fact the many elements of the engineering analysis are indeterminate at the present. These elements include: the installation cost of the PV systems, the value of electricity in the future, the value of the SREC in the future, etc. Considering reasonable ranges (highs and lows) for each of these potential values would change the value of PV systems over their lifetime. In order to find the range of these risks, many trials were constructed in the model for the different possible but likely fluctuation of these indeterminate values. The economic model was formulated over all these trial runs to create an expected value of Net Project Benefits for the project over the next 20 years. Given the statistics of 45 trials, there is a resulting $95 \%$ confidence interval that the project will create net value worth between $\$ 1.4$ and $\$ 6.3$ million dollars with an expected value of a little over $\$ 3.8$ Million (see Figure 8). The $90 \%$ confidence interval is $\$ 1.8$ to $\$ 5.9$ million dollars. 


\section{Expected Value of PV Project}

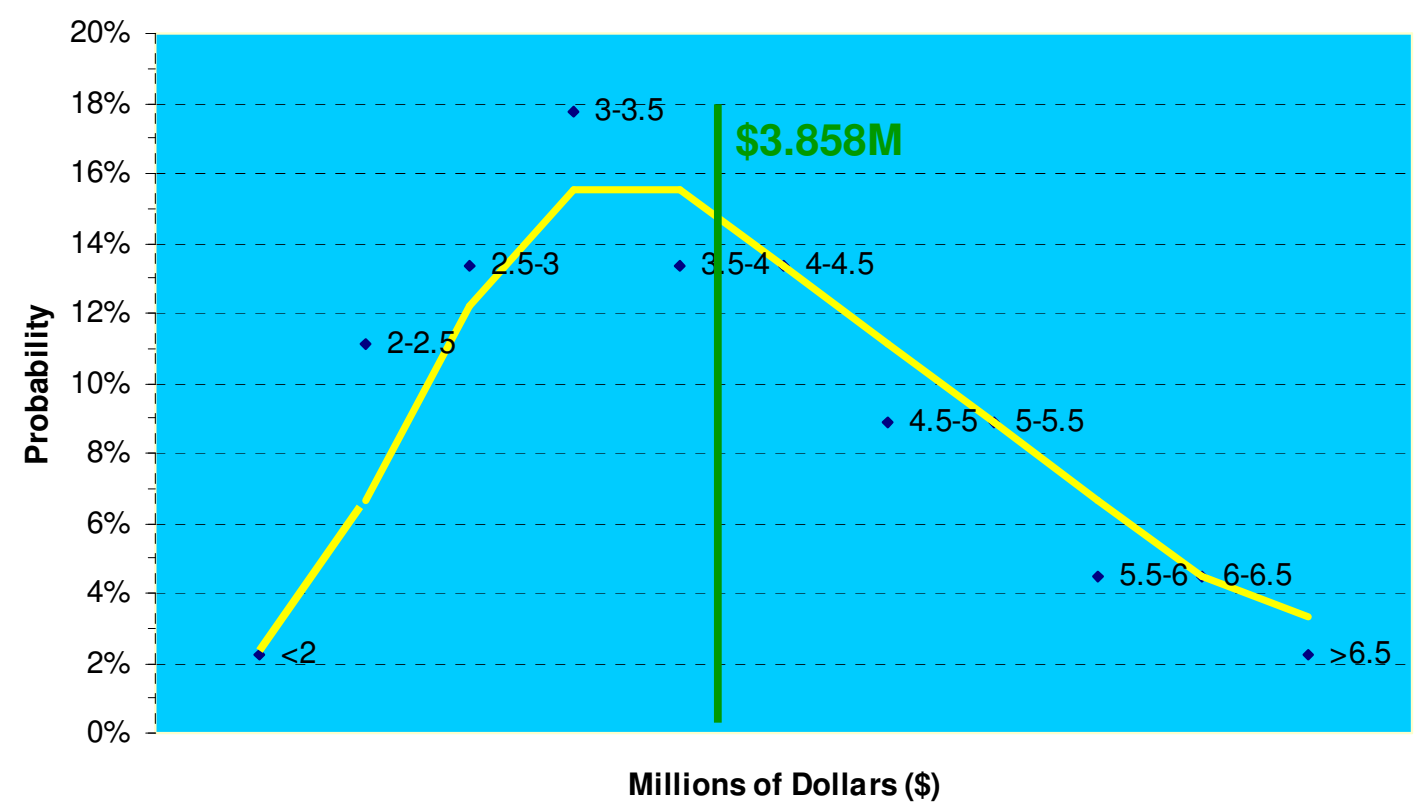

Figure8: Long-term economic model for expected value

\section{Conclusion}

In the process of performing the study, the engineering students learned many elements of real world engineering and were exposed to cutting edge electrical generating technology. One of the primary lessons learned by the students in this clinic experience was that a key element in establishing and completing the project goals was proper communication. Communication was vital throughout the project as 1) other engineers and building technicians were consulted for gathering data, 2) NJCEP representatives were contacted to ensure proper filing of rebates, worksheets, and designs, and 3) the City of Ocean City was updated frequently with the progress of the study, refocusing where the detailed engineering time should be spent and eliminating some potential sites from further review, etc. Perhaps most importantly the written and verbal communication required to properly inform the client of the final results and recommendations of the feasibility assessment. This puts a heavy responsibility on the engineer as consultant and requires thoroughness.

Having received the report of our analysis, the City of Ocean City clearly saw the value of this opportunity to utilize solar energy. The project has now moved into its next phase of specification, bid solicitation, evaluation and award. The City is hoping to interest a third party developer to participate in the financing, construction and operation since it is spending its immediate budget on critical expenses such as beach replenishment. The economic incentive is large but may not be a sufficient incentive to encourage the City to make such a large capital investment themselves. From our study it is clear that the benefits of this investment reach beyond the economic scope alone and will also directly benefit the environment. This effort will save nearly 1,000,000 pounds of greenhouse gas emissions annually (over 465 tons) to mitigate 
the possible threat of global climate change especially critical to the future viability of a shore community.

The students involved in this project based learning experience were positive about the impact it had on their ECE education. They commented that this real-world experience benefited them in numerous ways that their academic courses did not. These included: the application of their text book knowledge (from Networks I \& II - DC and AC circuits) to real problems for which an engineering consulting firm had been hired, the extension of their text book knowledge into National Electric Code requirements, real wire sizing, assessing solar windows via application of the Solar PathFinder ${ }^{\mathrm{TM}}$ and software, economic analyses, and PV system design and feasibility assessment. Overall, they believed it was a worthwhile complement to the education they were receiving at the College of Engineering in Rowan University.

\section{Bibliography and References}

1 J. L Schmalzel, A. J. Marchese and R. P. Hesketh, "What's brewing in the Clinic?," HP Engineering Educator, 2:1, Winter 1998, pp. 6-7.

2 J. L Schmalzel, A. J. Marchese, J. Mariappan and S. A. Mandayam, "The Engineering Clinic: A four-year design sequence," presented at the 2nd An. Conf. of Nat. Collegiate Inventors and Innovators Alliance, Washington, D.C., 1998.

${ }^{3}$ NJCEP Rebates http://www.njcep.com, New Jersey Clean Energy Program

${ }^{4}$ NJBPU Press Release http://www.njcleanenergy.com/html/5library/pdf/PR041206.pdf, "New Jersey Leads the Nation with Expanded Commitment to Solar and Clean, Renewable Energy"

${ }^{5}$ New Jersey Clean Energy Program Eligibility \& Guidelines http://www.njcep.com/html/3_eligib_guide.html

${ }^{6}$ NJCEP Solar Renewable Energy Certificates http://www.njcep.com/srec/index.html

7 SUNPOWER SPR-220 PV Module Specification Sheet http://www.sunpowercorp.com/pdf/SPR-220.pdf

${ }^{8}$ S. Hazel and P.M. Jansson, "Photovoltaic System Feasibility Assessments: Engineering Clinics Transforming Renewable Markets," ASEE Annual Conference, June 18-21, 2006:

${ }^{9}$ Solar Pathfinder, "How the Solar Pathfinder Works" http://www.solarpathfinder.com/works.html

${ }^{10}$ Solar Pathfinder Official Website http://www.solarpathfinder.com,

11 M.W. Early, J.V. Sheehan, et al., National Electric Code 2005 Edition, National Fire Protection Association,

12 New Jersey Clean Energy Program SREC Trading Statistics http://www.njcep.com/srec/trading-statistics.html

13. G. A. Masters, "Renewable and Efficient Electric Power Systems," John Wiley \& Sons, Inc. 2004. 